\title{
LENGUAS MARGINADAS EN LOS MANUALES DE LEXICOGRAFÍA DEL ESPAÑOL
}

\section{MARGINALISED LANGUAGES IN SPANISH LEXICOGRAPHY HANDBOOKS}

\author{
Luis Pablo Núñez ${ }^{1}$ \\ Universidad de Granada \\ luispablo@ugr.es
}

\begin{abstract}
RESUMEN
Este estudio analiza los principales manuales que abordan la historia de la lexicografía escritos en español y en inglés. A través del contraste de los contenidos tratados en unos y en otros, se exponen las diferentes perspectivas en el estudio de los diccionarios de la tradición hispánica y de la tradición académica anglosajona. Este contraste deja ver con claridad carencias en los manuales de lexicografía del español, especialmente en lo que se refiere a la ausencia de estudios sobre la lexicografía de muchas lenguas del mundo. Para solucionar estas carencias, se propone tener una mayor amplitud de miras más allá de Europa para crear manuales más completos o, incluso, traducir alguno de los anglosajones más relevantes. No obstante, sería preferible realizar uno de nueva planta que aborde de forma integral y actualizada la lexicografía del español con otras lenguas del mundo con las que ha entrado en contacto a lo largo de la historia.

Palabras clave: Lexicografía del español, lexicografía del inglés, Metalexicografía, Historia de los diccionarios, lenguas marginales, tradición académica anglosajona.
\end{abstract}

\section{Abstract}

This study analyses the main handbooks on history of lexicography published in Spanish and English. By contrasting their contents, the different perspectives considered in the study of dictionaries by the Hispanic academic studies versus the Anglo-Saxon ones are shown. This contrast clearly reveals shortcomings in the Spanish lexicographical handbooks, such as languages of the world never considered. In order to remedy these shortcomings, it is proposed to broaden the perspective of Spanish handbooks beyond Europe or even to translate into Spanish some of the most relevant Anglo-Saxon handbooks. However, it would be preferable to produce a new one which fully narrates -in a comprehensive and updated way- the history of Spanish lexicography and other languages of the world with which Spanish has been in contact throughout history.
\end{abstract}

Keywords: Spanish lexicography, English lexicography, Metalexicography, History of dictionaries, nonEuropean languages, Anglo-Saxon academic tradition.

${ }^{1}$ Dpto. Lengua Española, Grupo HUM-265 "Léxico y discurso". ORCID: 0000-0002-6491-6873; WoS ResearcherID: C-1340-2017; Scopus Author ID: 35812369600. 


\section{CARENCIAS EN LA HISTORIA DE LA LEXICOGRAFÍA DEL ESPAÑOL}

La historia de la lexicografía del español es cada día más completa, pero, a pesar de los significativos avances, sigue contando con carencias.

Una de estas carencias se refiere a la realización y estudio de repertorios bilingües con el español y otras lenguas periféricas o marginales, entendiendo por marginales no ya tanto las lenguas minoritarias, sino las de otras regiones alejadas cultural o geográficamente de España y de Hispanoamérica, esto es, las que quedan al margen de los intereses o ámbitos de contacto frecuente.

Los principales manuales de Lexicografía del español, en su parte referida a la historia de los diccionarios en su relación con otras lenguas, raramente incluyen información sobre las lexicografías bilingües o multilingües del español con las lenguas africanas, asiáticas o polinesias, ni tampoco de sus respectivas lexicografías monolingües: ¿significa esto que no existan, que no haya un contacto histórico con el español o que no contemos con diccionarios bilingües con algunas de ellas en nuestros días? Lexicográficamente hablando, para un hispanohablante, el mundo se reduce esencialmente a las lenguas europeas (y, dentro de ellas, a las más cercanas: francés, inglés, italiano, alemán, portugués, holandés; la lexicografía bilingüe del español con el danés, el griego moderno, el húngaro, el lituano, el polaco, el sueco y tantos otros idiomas de Europa $^{2}$ no figuran en los manuales que analizan nuestra lexicografía, o lo hacen apenas con unas líneas).

La visión occidental de nuestra lexicografía se ve en cierta medida paliada por la consideración de algunas lenguas alejadas, pero entroncadas por causas

\footnotetext{
${ }^{2}$ Recordemos que la Unión Europea cuenta, como unidad política, con 24 lenguas oficiales (siendo sus denominaciones, según el orden con que figuran en la documentación oficial: búlgaro, checo, danés, alemán, griego, inglés, español, estonio, finés, francés, irlandés, croata, húngaro, italiano, lituano, letón, maltés, neerlandés, polaco, portugués, rumano, eslovaco, esloveno, sueco. Fuente: UE, lenguas oficiales, https://cutt.ly/JR6Ucgk). A estas habría que añadir otros idiomas cooficiales, como los peninsulares, y los de otros países fuera de la Unión, pero históricamente europeos, como Noruega o Islandia, e incluso colindantes, como Marruecos, Turquía y Rusia.
} 
históricas con la española: es lo que ocurre con el estudio de los repertorios léxicos de las lenguas indígenas hispanoamericanas, estudiadas por la Lingüística misionera (pero fundamentalmente para los siglos XVI a XVII y, en mucha menor medida, el XVIII), y de la lexicografía hispano-árabe, debido al pasado andalusí (pero bastante menos analizada en lo que se refiere a la lexicografía de nuestros días y a los repertorios de español con los dialectos árabes). La lexicografía bilingüe del castellano con otras lenguas peninsulares oficiales, como el gallego, el catalán/valenciano/mallorquín o el vasco, tampoco suele estar presente en los manuales generales de historia de la lexicografía, siquiera con una breve síntesis.

Esta visión española peninsular predominante también se impone a las descripciones léxicas de los repertorios de español con otras lenguas americanas de uso actual - guaraní, quechua, aimara, etc.—, que existen, pero en editoriales locales, probablemente por ser grupos editoriales españoles de España los que habitualmente crean los manuales de la disciplina.

Esta no es la única carencia. Tampoco está debidamente realizada la descripción y análisis de los diccionarios especializados del español desde el punto de vista histórico -a pesar de los avances significativos de los grupos de investigación (europeos) de la Red temática Lengua y Ciencia 3 - ni suelen incluirse apartados en los manuales de lexicografía sobre los vocabularios técnicos (de la automoción, la industria aeronáutica o ferroviaria o de otras muchas áreas técnicas o biosanitarias, etc.), ya sean de carácter monolingüe o bilingüe y multilingüe, pues se da por hecha una separación tácita entre las obras lexicográficas académicas (de la Real Academia Española) y las realizadas por las restantes academias (de Ciencias, de Ingeniería, de Medicina), así como entre los repertorios de carácter general y los de carácter especializado, tratados más en otros ámbitos menos filológicos, como los traductológicos.

${ }_{3}^{3}$ Para mayor información, veáse su página electrónica: https://www.lenguayciencia.net/. 
Otro vacío significativo, aunque algo menor, está en la escasa descripción de la lexicografía bilingüe contemporánea, la lexicografía de nuestros días, algo que contrasta con la tradición metalexicográfica anglosajona, más atenta a las obras actuales con un mayor número de lenguas. Puede que estos estudios existan parcialmente en forma de artículos o capítulos en actas de congresos, pero este conocimiento no está incorporado a los manuales de la disciplina, quizá por aparecer en publicaciones con poca difusión o por no haber sido debidamente valorados para ser recogidos en los manuales.

\subsection{OBjeTIVOS y METOdología de ESTE ESTUdio}

Este trabajo tratará de mostrar algunas de estas carencias en los siguientes apartados y de proponer posibles soluciones. Para ello, en este artículo haremos un análisis de cuáles son las lenguas tratadas en los principales manuales generales de lexicografía escritos en inglés y en español. El contraste con los manuales del inglés y no de otras lenguas -francés o italiano, por ejemplo- se debe a que esta lengua es la que ha creado más manuales importantes que se han convertido en referencia de la disciplina. Esto supondrá repasar los materiales existentes hasta el momento, lo que también será una aportación interesante para conocer el estado de la cuestión sobre la historia de la lexicografía.

Metodológicamente, analizaremos de forma contrastiva qué lenguas son tratadas tanto en unos manuales como en otros, ya expongan la historia de la lexicografía española o anglosajona (normalmente, los escritos en español abordan la lexicografía monolingüe, bilingüe y multilingüe del español, y del mismo modo los anglosajones la del inglés), pero nos interesa mostrar especialmente cómo se aborda la lexicografía bilingüe, esto es, la relación entre los diccionarios del español o inglés y otras lenguas.

Es de interés señalar que, en el ámbito anglosajón, la lexicografía es abordada primeramente desde una perspectiva más práctica, esto es, la de las técnicas para elaborar léxicos o diccionarios (según la definición de 
los diccionarios Collins ${ }^{4}$, lexicografía es "the activity or profession of writing dictionaries"). Esto se refleja en la existencia de manuales que, partiendo de aspectos teóricos, buscan su aplicación práctica (cf. los de Landau, 1984, 2001² sobre The art and craft of Lexicography, Van Sterkenburg, 2003 y Atkins/Rundell, 2008); otros manuales abordan, generalmente de manera separada, la perspectiva histórica. En los manuales escritos en español puede darse también esta separación, pero es mucho más frecuente la inclusión de ambas perspectivas en un mismo manual, la teórica y la histórica, ya sean de autoría individual o colectiva, al ir dirigidos en buena medida a estudiantes universitarios.

Este tratamiento diverso también está motivado por el mayor o menor peso que tiene en cada trayectoria académica la tradición metalexicográfica: así, de entre las varias perspectivas con que se puede abordar la lexicografía según Wiegand (1984) (teoría general de la lexicografía, investigación sobre el uso de diccionarios, historia de las obras, crítica de diccionarios), en el ámbito europeo románico los autores españoles, franceses e italianos se han centrado mayormente en el estudio histórico de los diccionarios monolingües y en el desarrollo posterior de las lexicografías nacionales -cf. los primeros trabajos de lexicografía del ámbito francés, como los de Quemada (1968), Matoré (1968), etc., y los muchos sobre la trayectoria de los diccionarios de la Academia Española-, mientras que los anglosajones y alemanes han preferido los estudios sobre los principios de elaboración de diccionarios y la lexicografía didáctica bilingüe.

Nuestra hipótesis de partida, comprobada en el manejo habitual de los manuales de lexicografía como docentes, es mostrar la poca representación o ausencia total de ciertas lenguas en los estudios sobre la historia de la lexicografía del español, es decir, la marginalización de lenguas en la lexicografía

4 Diccionario monolingüe Collins COBUILD en línea, s.v. lexicography https://cutt.ly/ uR6UY1C [consulta: 12/10/2021]. 
española, a pesar de la existencia de diccionarios bilingües antiguos o recientes con muchas de ellas.

\section{LA HISTORIA DE LOS DICCIONARIOS EN LOS MANUALES DE LEXICOGRAFÍA}

\subsection{Manuales de lexicografía en español}

La historia de la lexicografía del español irrumpió con fuerza en los estudios de metalexicografía hispanos desde los años noventa del pasado siglo XX y hoy es una de sus líneas principales. Cuenta con grupos de investigación dedicados a ella directa o indirectamente en la Universidad Complutense, la Universidad de La Coruña, la de Jaén y Granada y la Autónoma de Barcelona, entre otras. El papel de ciertos maestros, como Manuel Alvar Ezquerra o Ignacio Ahumada Lara, ha promovido el desarrollo de estudios históricos entre sus discípulos. Si hace unas décadas esta historia era irrealizable porque apenas contábamos con estudios, hoy son tantos que lo difícil es realizar una síntesis ajustada; no obstante, como decíamos, todavía hay carencias.

Sin ánimo de ser exhaustivos, entre los manuales recientes dedicados a narrar la historia de la lexicografía española podemos destacar varios:

Los Cinco siglos de lexicografía del español de Ahumada Lara (2000) surgió como publicación del Seminario de Lexicografía Hispánica que se organizaba anualmente en la Universidad de Jaén (concretamente, de su cuarto seminario, en noviembre de 1999), pero el resultado es una monografía amplia sobre la historia de la lexicografía española, monolingüe y bilingüe, realizada por varios autores. En el caso de la bilingüe, las lenguas tratadas aquí con el español son el latín, el griego, el inglés, el árabe, el vasco y, en otro capítulo conjunto, las obras de español con otras lenguas románicas (francés, italiano, rumano; las lenguas contenidas en este y otros manuales luego descritos aparecen recogidas en la tabla recapituladora del punto 2.3). 
El de Bajo Pérez (2000) incluye una introducción breve a la historia de la lexicografía del español realizado de forma sintética, pero muy clara; analiza los diccionarios de acuerdo con su tipología mediante fichas monográficas, con especial atención a los más recientes, pero fundamentalmente monolingües.

El coordinado por Medina Guerra (2003) está dividido en tres partes: la primera, sobre teoría de la lexicografía, y la segunda, la más amplia, sobre la historia de la lexicografía por épocas y tipos de diccionarios; la tercera trata la lexicografía didáctica. Como obra colectiva, cada capítulo está elaborado por un especialista. Por el número de lenguas que aborda, es uno de los más completos: además de la lexicografía con el latín y con otras lenguas cooficiales, aborda en su segunda parte la bilingüe con el inglés, francés, alemán, neerlandés, italiano, portugués, rumano y, aunque de forma breve, también las de lenguas amerindias y de Asia (idiomas de Filipinas y chino).

El de Anglada Arboix (2002) es el curso impartido por esta profesora en la Universitat de Barcelona; junto con los capítulos que delimitan los objetivos de la asignatura, la tipología de obras y el análisis de su estructura, se incluyen tres que recorren los diccionarios del español desde los orígenes hasta finales del siglo XX (pp. 13-90, lo que es casi la mitad del libro). Aunque no muy profundo, es interesante porque muestra con reproducciones páginas de los diccionarios y plantea ejercicios. Describe las obras bilingües cronológicamente, destacando los hitos de cada una de sus épocas, pero no se abordan más que los repertorios bilingües con las lenguas más próximas, como el francés, italiano, portugués y el latín en el capítulo II; el capítulo III y IV, que cierra la descripción histórica, solo recoge monolingües. Salvando el de Mascareñas del siglo 
XIX (con portugués), no se mencionan otros bilingües posteriores al siglo XVII, y a los del inglés y alemán solo se hacen pequeñas menciones en dos párrafos de la página 32.

El manual en catalán de Rafel i Fontanals (2005) es un manual descriptivo de la disciplina y de sus técnicas (conceptos, tipología de diccionarios, estructura, definición lexicográfica), al estilo del de Porto Dapena (2002), pero más sintético; no incluye ningún apartado sobre historia.

El de Martínez de Sousa (2009) recoge en un nuevo formato parte de lo escrito en su útil Diccionario de lexicografía práctica (1995), con muchas actualizaciones y un nuevo orden temático. Es interesante por los capítulos sobre tipografía, del que el autor es especialista, y sobre lexicógrafos ilustres -ordenados cronológicamente por la fecha de su nacimiento, hasta 1970-, de los que da su biobibliografía. Como gran obra de síntesis de todos los aspectos posibles, solo las páginas 239 a 241 trazan la historia de los diccionarios, desde la antigüedad clásica a nuestros días, pero aquí solo recoge la tradición francesa, italiana, alemana y anglosajona, pues la española, catalana y gallega (fundamentalmente, monolingüe) figura páginas después, de la 250 a la 272.

La Historia de la lexicografía española de Campos Souto/Cotelo García/Pérez Pascual (2007) es, como el coordinado por Ayala Castro/Medina Guerra en 2010 o por Sariego López/Gutiérrez Cuadrado/Garriga Escribano, 2017, un volumen colectivo de algunos de los estudios presentados en los congresos que realiza cada dos años la AELex, Asociación Española de Estudios Lexicográficos, nacida en 2002. Son aportaciones relevantes, pero no una historia completa en sí, a pesar del título. 
Similar a las actas de congresos son los dos volúmenes sobre la Lexicografía de las lenguas románicas editado por Córdoba Rodríguez/González Seoane/Sánchez Palomino (2014) publicado por De Gruyter. La obra, surgida de la Red de Lexicografía (RELEX) tiene mucho interés, pues da una visión actualizada de la lexicografía española, gallega, vasca, rumana y sarda, con otros trabajos relativos a obras particulares.

La Introducción a la lexicografía de Rodríguez Barcia (2016) publicado en Síntesis es uno de los últimos manuales de conjunto sobre la disciplina. Como otros volúmenes que parten de la experiencia docente de sus autoras, este incluye capítulos sobre conceptos y análisis de la estructura de los diccionarios, pero también otros sobre la crítica lexicográfica y la elaboración de diccionarios, así como sobre la lexicografía en línea y para dispositivos móviles (la cual, por cierto, está muy poco tratada en otros manuales o ha quedado desactualizada). La historia de los diccionarios se aborda en su primer capítulo, donde repasa la "historia de la lexicografía en España a través de diez hitos": las glosas, las obras de Nebrija y Covarrubias, El Diccionario de autoridades, el de Terreros, un balance de los del siglo XIX, el de María Moliner y el de Manuel Seco, Olimpia Andrés y Gabino Ramos, el Diccionario panbispánico de dudas y el DLE. La inclusión de diccionarios bilingües es escasa.

Los mostrados arriba son los que podrían denominarse, en modo amplio, como manuales. Pueden citarse otros, es cierto, como el de Haensch/Wolf/ Ettinger/Werner (1982), publicado en Gredos, pero su propósito es situar la lexicografía entre las disciplinas lingüísticas y no aborda la historia de los diccionarios. 
Otras obras de investigadores emblemáticos en el desarrollo de la historia de la lexicografía del español, como la de Alvar Ezquerra (2002) o la de Álvarez de Miranda (2011) sobre los diccionarios del español moderno, no son tanto manuales como recopilaciones de trabajos previos que se han ordenado cronológicamente siguiendo la época de los diccionarios de los que tratan (así, el de Álvarez de Miranda recoge "una decena de estudios que derivan de catorce trabajos - publicados entre 1992 y 2008- sobre historia de la lexicografía española", fundamentalmente monolingües). No obstante, sobre los repertorios temáticos o nomenclaturas el estudio más completo hasta el momento sigue siendo sin duda el de Alvar Ezquerra (2013), que incluye tanto las de las principales lenguas europeas como alguna filipina, si bien paulatinamente van conociéndose nuevas obras que allí no se incluyen y que completarán el panorama (de una nomenclatura hispano-turca y de otra hispano-francesa del siglo XVIII aún no estudiadas trataremos en otros trabajos).

Del mismo modo, otros volúmenes publicados con motivo de homenajes (a José Antonio Pascual: Quirós García et al., 2016; a Antonio Martínez: Martínez González, 2017, etc.) también incluyen estudios de diccionarios o vocabularios del español, estudios etimológicos y de historia del léxico, pero no una historia completa.

De interés para este repaso son, asimismo, los monográficos dedicados a la historia de la lexicografía del español en revistas: el primero apareció en el número 3 del volumen 8 de International Journal of Lexicography ${ }^{5}$. Esta revista dedicó en 1995 un monográfico con varios artículos sobre la historia de los diccionarios del español, el diccionario histórico o el diccionario de construcción y régimen a cargo de Manuel Alvar Ezquerra, Manuel Seco o Ignacio Ahumada, con textos en español, pero queda lejos de ser una historia. El segundo, más completo y actual, dedicado a la lexicografía bilingüe

${ }^{5}$ DOI 10.1093/ijl/8.3.167 
y plurilingüe del español, se publicó bajo la coordinación de Manuel Bruña Cuevas en el número 22 de la revista Philologia hispalensis. Contenía capítulos sobre la lexicografía plurilingüe de los siglos XVI y XVII, la lexicografía bilingüe español-latín, español-árabe, español-francés, español-alemán, español-italiano, español-portugués y otros sobre la lexicografía hispano-amerindia del siglo XVI y ciertas obras concretas del catalán, del vasco y del inglés. Otras lenguas europeas no están representadas, ni tampoco las asiáticas o africanas. El acceso a los textos es abierto desde la página de la revista o de Dialnet.

Ahora bien, es cierto que existen obras específicas que se han centrado en la descripción de ciertas lexicografías bilingües del español: así, los tres volúmenes dirigidos por Félix San Vicente analizan con profundidad los más relevantes de la historia de la lexicografía italo-española desde 1805 a 2007 (San Vicente 2008 y 2010; la parte anterior fue tratada por Gallina, 1959) y, del mismo modo podría decirse con la hispano-francesa (cf. Cazorla Vivas, 2002, Pablo Núñez, 2010), la hispano-inglesa (Steiner, 1970, con reed. en 2015, y Fernández Urdaneta, 2010), etc.; estas obras nacieron generalmente como tesis doctorales, aunque también hay monografías publicadas sin serlo, como la relativa a los vocabularios hispano-filipinos de García-Medall Villanueva (2009).

Un balance sintético, pero relativo solo a un cierto periodo, siglos XV a XVII (con repaso por la lexicografía bilingüe español-latín, español-inglés, francés, alemán, neerlandés, italiano y repertorios multilingües), se puede ver en línea en el Portal de Historia de la traducción en España de la Universitat Pompeu Fabra (Pablo Núñez, 2020).

Mencionaremos también la obra de Günther Haensch (2004), Los diccionarios del español en el siglo XXI, con dos ediciones, la segunda de las cuales muy aumentada, que destaca por su capacidad de síntesis y por la claridad con que analiza los tipos de diccionarios más recientes. Su capítulo 3.4.1.5 cita algunos diccionarios de los siglos XVIII y XIX, pero solo por su título, y el 
3.4.2 analiza muy brevemente algunos diccionarios bilingües "disponibles en el mercado" del griego y latín clásicos con español, inglés, francés, alemán, italiano, portugués, árabe, catalán, gallego y vasco; concluye el balance con una reflexión sobre las "luces y sombras en la lexicografía bilingüe española en el siglo XXI" (p. 296).

Necesarios también para trazar la historia de la lexicografía del español son los cinco volúmenes de la Bibliografía cronológica de la lingüística, la gramática y la lexicografía del español (BICRES) de Niederehe/Esparza Torres (1994 a 2015, diferentes vols.), inspirada en la Biblioteca histórica de la filología (1893) del conde de la Viñaza; no obstante, frente a aquella, aquí no se estudian las obras, sino que se acumulan las noticias bibliográficas sobre ellas dispersas en multitud de catálogos. De manera complementaria, la Biblioteca Virtual de la Filología Española (BVFE) es un catálogo bibliográfico que remite, como ya hicimos en nuestra tesis doctoral (cf. catálogo de Pablo Núñez, 2010), a los ejemplares digitalizados en línea de obras no solo lexicográficas, sino también ortográficas o gramaticales.

Tras este somero repaso de las principales fuentes que describen la lexicografía del español, reseñaremos algunas otras en inglés, para saber cómo analizan la historia de los diccionarios los manuales de lexicografía anglosajones. A través de esta comparación veremos las aportaciones y diferentes visiones a la hora de estudiar los diccionarios bilingües en una y otra tradición académica.

\subsection{Manuales de lexicografía en inglés}

De los muchos manuales del inglés sobre lexicografía, destacaremos solo aquellos que pueden ser pertinentes para nuestro análisis. Existen muchos: por ejemplo, el de Zgusta (1971), uno de los más antiguos, define los principales elementos de la disciplina, desde la consideración de la palabra y sus aspectos semánticos, su variación formal, combinatoria, tipología de diccionarios y la realización de diccionarios, pero no incluye ningún apartado sobre la historia de los diccionarios. De la misma manera ocurre en otros más recientes: la obra colectiva editada por Van Sterkenburg (2003) se refiere a 
tipología de diccionarios, usuarios y usos; incluye también apartados sobre el diseño de diccionarios, el manejo de corpus y la realización práctica de entradas, pero nada sobre historia.

El manual editado por Jackson (2013) en Bloomsbury tampoco narra la historia: incluye capítulos de una veintena de autores, como Paul Bogaards, John Considine, Pedro A. Fuertes-Olivera o Robert Lew, sobre aspectos como la aplicación de la tecnología para la realización de diccionarios electrónicos, la ordenación de acepciones, el uso de corpus como fuentes para la composición de diccionarios o la lexicografía histórica y los diccionarios etimológicos. Evidentemente, la investigación sobre lexicografía tiene ya tantos enfoques posibles que no es posible abordarlos todos.

El volumen History of Lexicography editado por Hartmann (1986) es, como vimos con algunos títulos españoles, el volumen de actas de un seminario que tuvo lugar en Exeter, en el Dictionary Research Centre. No es, por tanto, una historia de la lexicografía propiamente dicha: partiendo de la lexicografía renacentista, contiene estudios sobre diccionarios concretos (el diccionario francés de Richelet, el Thesaurus de John Wilkins, Palsgrave, etc.), pero también otros más generales sobre la lexicografía bilingüe china, la inglés-árabe, la húngara y escandinava o los diccionarios croatas, lo que en cierto modo justifica el título, aunque sea parcial; al final se hace un balance de la lexicografía hispano-inglesa por Roger J. Steiner.

Si nos centramos en los manuales de Lexicografía publicados por tres de las principales editoriales anglosajonas (Oxford University Press [OUP], Cambridge, Routledge), vemos en parte algo similar: el de Cambridge, editado por Svensén (2009), traza un buen panorama sobre la lexicografía y las disciplinas con las que se interrelaciona, los tipos de diccionarios, la selección de fuentes, la inclusión de ejemplos, las ilustraciones y los puntos necesarios para la planificación de un diccionario, pero no aborda la historia. El de Routledge, editado por Fuertes-Olivera (2018), es una obra colectiva que aborda la problemática intersección entre la lexicografía y otras 
disciplinas, los distintos tipos de diccionarios según su finalidad -traducción, producción, asistencia para la enseñanza-aprendizaje- y se detiene con preferencia en la lexicografía digital, especialmente en línea. Es en este último apartado donde incluye una descripción del estado de la lexicografía actual en distintas lenguas: "African lexicography in the Internet era", "Arabic lexicography in the Internet era", "Chinese...", "English...", "French...", "German...", "Hindi...", "Indonesian...", "Portuguese...", "Russian..." y "Spanish lexicography in the Internet era”. Este último está escrito por Ignacio Bosque y Auxiliadora Barrios y es un balance sintético de los diccionarios más recientes y de los estudios dedicados a ellos; señalan también diccionarios en línea con español y otros bajo agrupaciones como "gramatical dictionaries", "phraseological dictionaries", "didactic dictionaries", "illustrated dictionaries", etc.

OUP tiene varios manuales sobre lexicografía: el editado por Atkins/Rundell (2008) trata específicamente sobre cómo hacer un diccionario, desde su proyecto inicial y la creación de una base de datos a la redacción de las entradas. El editado por Durkin (2016) se divide en varias partes: la primera sobre diccionarios sincrónicos; la segunda, sobre los históricos; la tercera, sobre diccionarios especializados; la cuarta trata otros enfoques concretos: hiperonimia, sinonimia, homonimia; representación de la pronunciación en diccionarios generales, inclusión de ilustraciones, diccionario e identidad nacional. Incluye al final una tabla cronológica sobre "major events in the history of Lexicography" (no solo ingleses, aunque sí en su gran parte) por John Considine. Como ocurre frecuentemente en este tipo de obras, la bibliografía cita estudios anglosajones en un 95\% y solo ocasionalmente alguna referencia en francés o alemán (española no vemos ninguna, aunque sí alguna en inglés escrita por investigadores españoles).

La historia de la lexicografía inglesa de la OUP (Cowie, 2009) traza en su primer volumen la historia de los diccionarios ingleses desde el periodo medieval hasta nuestros días. Obra colectiva, distingue en dos grandes partes 
entre los primeros repertorios bilingües y multilingües y los monolingües. Algunos otros capítulos complementarios van dedicados al Oxford English Dictionary, a los diccionarios del inglés caribeño, a los diccionarios estadounidenses. Si el primer volumen se ciñe a los repertorios generales, el segundo se centra en los específicos, pero los analiza no por cronología, sino por su tipología: diccionarios de pronunciación, de nombres propios, etimológicos, técnicos, electrónicos...).

Los manuales anglosajones raramente mezclan en una misma obra cuestiones de teoría de la lexicografía e historia, como dijimos más arriba: como norma general, se dedican por entero a uno u otro enfoque.

Existen, no obstante, obras mixtas: Landau (1984, 2001²) dedica 55 páginas -de las 370 totales de la primera edición, 480 en la segunda- a una breve historia de la lexicografía inglesa ("A brief history of English lexicography", pp. 43-97), e incorpora un apéndice de "Dictionaries mentioned in the text, from Johnson (1755) to the present: a bibliography and index".

Del mismo modo excepcional, capítulos sobre historia de la lexicografía de lenguas de todo el mundo -"African Lexicography", "Arabic Lexicography", "Australian Lexicography", "Bulgarian Lexicography", "Canadian Lexicography", "Croatian Lexicography","Czech Lexicography", "English Lexicography", "Estonian Lexicography", "Finnish Lexicography", "French Lexicography", "German Lexicography", "Greek Lexicography, Modern", "Hebrew Lexicograhy", "Japanese Lexicography", "Korean Lexicography", "Latvian Lexicography", "New Zealand Lexicography", "Polish Lexicography"..., "Spain: Lexicography in Iberian Languages", etc.- también se pueden encontrar en la Encyclopedia of Language and Linguistics (Brown/Anderson, 2006), pero esta monumental obra de catorce volúmenes no es una historia de la lexicografía ni pretende serlo: aunque encontramos más lenguas descritas que en muchos manuales, sus entradas no pueden tener más de unas ciertas páginas (algunas, solo dos) y la lexicografía no es sino una disciplina de las muchas que abarca; además de la edición impresa, cuenta con materiales audiovisuales complementarios en línea. 
Se han publicado, no obstante, otros manuales: el International Handbook of Modern Lexis and Lexicography de la alemana Springer (Hanks/De Schryver, eds., 2015-2024), con publicación en marcha desde 2015, pretende dar un panorama de la lexicografía más reciente, y para ello también incluye la historia de la lexicografía. Dedica capítulos a lenguas no solo europeas, sino también a otras lenguas indígenas y lenguas en riesgo de desaparición: así, además de la lexicografía escocesa, alemana y noruega, aborda las lenguas indígenas de Australia y el Pacífico, "The lexicography of Khmer" (lengua jemer, hablada en Camboya, Tailandia, Vietnam) o "The lexicography of Indonesian/Malay". En otro capítulo, sobre la lexicografía de las lenguas indígenas de Sudamérica, traza un balance resumido de los primeros diccionarios del quechua, aimara, tupí y tupí-guaraní y de otras lenguas amazónicas y de las Antillas. Es llamativo que su autor sea Wolf Dietrich y no un hispanohablante. Como la obra está actualmente en preventa, solo conocemos algunos de sus capítulos.

Finalmente, quedan por citar dos obras significativas que abordan la historia de la lexicografía mundial:

A los tres volúmenes de la enciclopedia internacional de Lexicografía editada por Hausmann et al. (1989-1991), la más amplia y completa hasta hace poco, aunque desactualizada en lo referido a la época actual, se añadió un cuarto suplemento en 2013 con los avances más recientes, con especial énfasis en la lexicografía digital ("Recent developments with focus on electronic and computational lexicography"). En estos volúmenes, tras las cuestiones teóricas del primero y gran parte del segundo, se analiza la historia de los diccionarios, desde las lenguas antiguas de Asia Menor y la antigua Grecia y Roma, a las lenguas romances (portugués, gallego, español -por Günther Haensch-, catalán, francés, italiano, rumano, provenzal, sardo y retorromance, judeoespañol), las lenguas germánicas 
(danés, noruego, sueco, inglés, escocés, inglés estadounidense, neerlandés, frisón, alemán, yiddish) y las lenguas eslavas (polaco, serbio, checo, eslovaco, serbocroata, esloveno, macedonio, búlgaro, ruso, ucraniano y bielorruso). El tercer volumen iba dedicado a la lexicografía de otras lenguas europeas menos frecuentes (finés, vasco, armenio, albanés, húngaro, estonio...) y de otras regiones extraeuropeas (turco, lenguas semíticas, lenguas iranias, lenguas del subcontinente indio, lenguas tibeto-birmanas, lenguas austronesias, del sudeste asiático, del Pacífico, de Mesoamérica y de Sudamérica). En total, 3300 páginas para los tres volúmenes, más otras 1600 del cuarto. La redacción es mayoritariamente en inglés, aunque también en alemán, francés y alguna en español.

Por último, hay que destacar la historia de la lexicografía mundial publicada por Cambridge University Press a finales de 2019 (Considine, 2019): en casi mil páginas, se repasa la lexicografía de todas las épocas y lugares, empezando por la del mundo antiguo (incluyendo Egipto, China e India), la de la época medieval europea (pero no solo de Europa: también del Próximo Oriente, del griego bizantino, de las lenguas turcas y del persa, del árabe, del hebreo...); la tercera parte se dedica al mundo moderno, incluyendo las lenguas románicas, eslavas y bálticas, y la parte cuarta y última al mundo moderno con especial atención a la lingüística misionera, tanto en América del Norte y del Sur como en Asia y África. Si bien se descarta entrar en profundidad en la lexicografía contemporánea, es la puesta al día más actualizada en la historia de la lexicografía, aunque no sea la más amplia en número de páginas. Los textos están escritos en inglés, pero nótese que no solo se aborda la lexicografía inglesa o la bilingüe con el inglés, sino, en general, la historia de los diccionarios de cada una de 
las lenguas. Esta obra está en consonancia con otras obras del editor (Considine, 2017), donde se presentan capítulos sobre la lexicografía del finés, del sueco y de lenguas menores, junto con otros breves apuntes sobre vidas de lexicógrafos y vocabularios manuscritos: aunque es una visión anglosajona, el punto de mira sobrepasa lo local.

\subsection{RecAPITULACIÓN}

Aunque probablemente no sean todos los trabajos existentes, sí creemos haber dado en este panorama un buen balance de los principales manuales de lexicografía publicados en lengua inglesa y española. Esto puede ser útil no solo para orientar sobre sus contenidos a los docentes, sino también para mostrar la diferente perspectiva a la hora de abordar la historia de la lexicografía por el mundo académico anglosajón: los manuales anglosajones optan por centrarse en la teoría y práctica del diccionario, por un lado, y en la historia de la lexicografía, por otra, normalmente en obras separadas.

La historia de la lexicografía se aborda en los manuales anglosajones desde una perspectiva global, con el fin de conocer el desarrollo e historia de los diccionarios de una lengua, ya sea en su carácter monolingüe o bilingüe con el inglés. Esto motiva la inclusión de un número de lenguas considerable. Esta perspectiva no existe en los manuales hispanos: son escasos los estudios en español que abordan en sí la historia de los diccionarios de otras lenguas europeas, africanas o asiáticas, y, cuando los hay, suelen centrarse en los bilingües con español. Puede que estos trabajos hayan aparecido en actas de congresos o revistas, pero han sido muy poco o nada valorados para su inclusión en los manuales (por ejemplo, los estudios sobre diccionarios con español-japonés, como los de Jacinto García, 2004 y Rojo-Mejuto, 2018 o el de García-Medall, 2009 sobre los hispano-filipinos). Por esto, la única manera de conocer la historia de la lexicografía con ciertas lenguas poco o nada tratadas en los manuales en español es 
recurriendo a las obras escritas directamente en las otras lenguas o bien consultando las síntesis creadas por los anglosajones: ante esto, una traducción al español de alguna de las principales obras anglosajonas podría paliar esta carencia.

Para finalizar, mostramos en forma de tabla las lenguas tratadas tanto en los principales manuales escritos en español como en los escritos en inglés. Aunque en un principio pensábamos dar una tabla para los manuales en español y otra para los escritos en inglés, finalmente hemos optado por reunir todo en una sola para mostrar con más claridad la comparación entre ellas.

Las obras citadas hacen referencia al editor señalado arriba, pero también a la editorial que ha publicado el manual, pues vemos que en el ámbito anglosajón esto es un elemento importante e identificativo.

La agrupación de lenguas se hace en bloques que se diferencian con colores y sigue este orden: lenguas clásicas (latín, griego, sánscrito, hebreo...); lenguas peninsulares (español más las cooficiales); lenguas europeas; lenguas no europeas: amerindias; africanas; de Asia; de Australia; lenguas del Pacífico. Los capítulos marcados con "(gral.)" (esto es, general) indican que existe un capítulo donde se habla de muchas lenguas de esa rama; el signo de verificación entre paréntesis $(\checkmark)$ indica que la obra trata, en efecto, esa lengua o lenguas, pero no con un capítulo propio, sino dentro en un apartado más amplio o general, o bien con poca extensión.

Como ya señalamos arriba, la ausencia de ciertos apartados o lenguas puede deberse a las limitaciones voluntarias establecidas por la propia obra, bien por ceñirse a un periodo concreto (por ejemplo, estudio de la lexicografía de los siglos XVI-XVII, o solo del siglo XX...), bien por su modalidad (estudio de lexicografía bilingüe o monolingüe únicamente): por ejemplo, la obra de Álvarez de Miranda (2011) se restringe a los siglos XVIII, XIX y XX (no incluye los anteriores) y, por no ser un manual propiamente dicho, no figura en la tabla. 


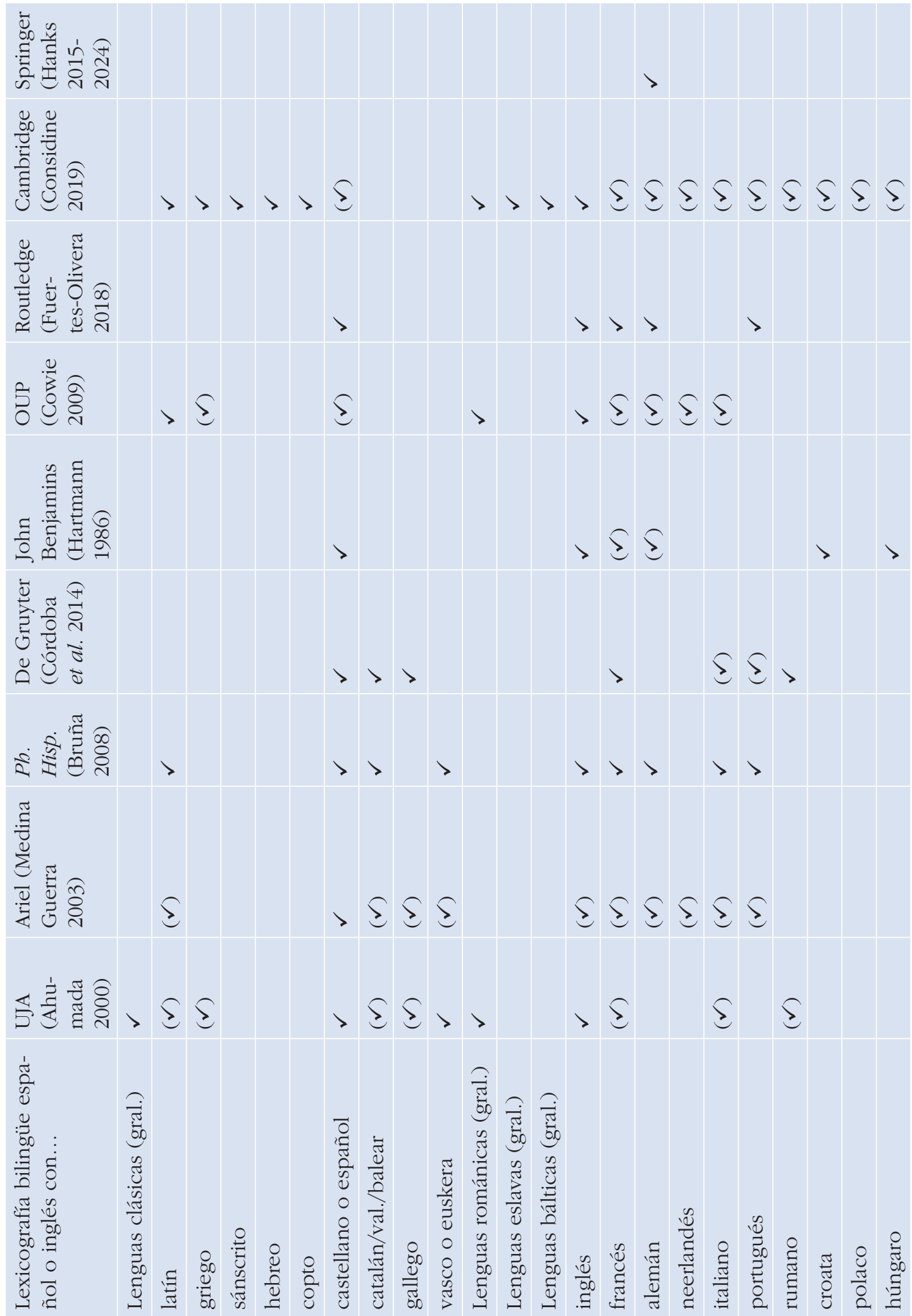




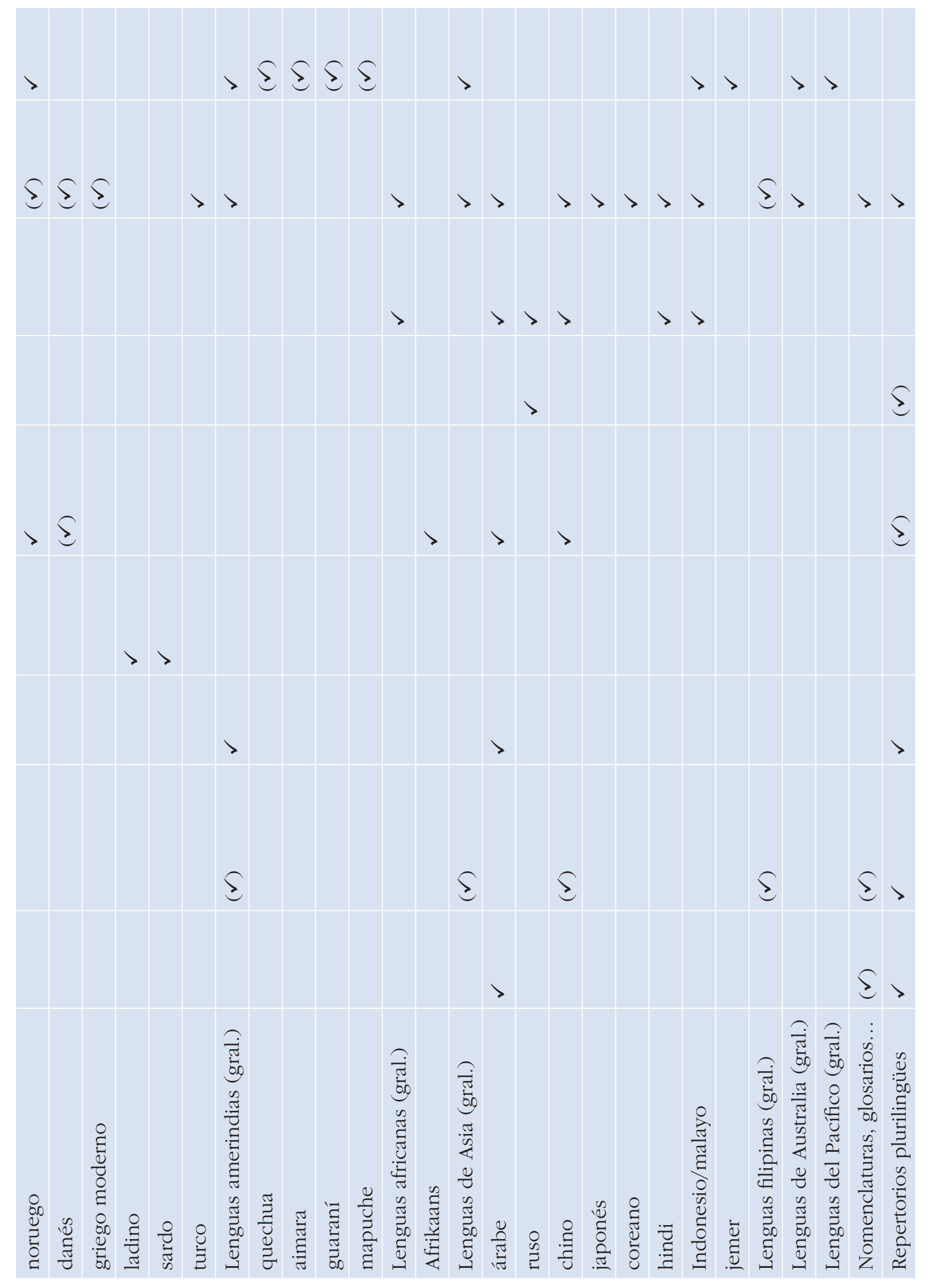




\section{COnClusiones}

Este trabajo ha mostrado, mediante el análisis de los contenidos en los principales manuales de lexicografía del español y del inglés, los diferentes enfoques tratados en la tradición académica hispánica y anglosajona.

Es evidente que no están incluidos todos los estudios posibles tanto en una lengua como en otra, que podrían haberse también buscado paralelos en otras lenguas (manuales de la disciplina en francés o italiano) y que ciertas áreas han podido ser tratadas más extensamente en monografías, pero, aun teniendo en cuenta esto, es patente que el objetivo de todos los manuales debería siempre ser dar una visión clara, sintética y lo más completa posible de la disciplina, resumiendo incluso trabajos previos o señalando al menos su existencia, lo cual no siempre se hace.

En el caso del español, muchos de los manuales existentes van dirigidos al estudiantado universitario y no al especialista, lo que motiva la falta de máxima exhaustividad o su número reducido de páginas; de hecho, algunos son consecuencia directa de la enseñanza en las aulas, como el de Anglada (2002) y el de Rodríguez Barcia (2016); otros, en cambio, han podido surgir de encuentros en congresos o seminarios y se han publicado como actas con una cierta unidad temática (por ejemplo, Hartmann, 1986 y Ahumada Lara, 2000). Destaca de entre todos los españoles señalados el coordinado por Medina Guerra (2003), el cual, además de ser bastante claro y probablemente el más completo, se asemeja mucho al de las grandes editoriales anglosajonas, que publican una obra tras proponer a un editor y a un colectivo de autores la realización de un manual.

Los manuales anglosajones que dedican alguno de sus apartados a analizar la lexicografía bilingüe con el español no contienen apartados para la lexicografía de las otras lenguas cooficiales peninsulares (catalán, gallego, vasco), de la misma manera que los manuales escritos en español tampoco mencionan el gaélico escocés o el galés al tratar los diccionarios del inglés. No obstante, se aprecia en la tabla que la lexicografía de buena parte de las 
lenguas de Europa ni las de otras regiones del globo figuran apenas en los manuales españoles y, cuando figura alguna, es con solo unos párrafos, lo cual es una gran carencia que debería ser corregida.

Queda por señalar que no contamos en español con una historia de la lexicografía mundial como la que se realizaron por Hausmann et al. (19891991) o Considine (2019), ni siquiera traducida del inglés o de otra lengua, ni parece haber en marcha un proyecto editorial para realizarlo (en otros ámbitos sí, como la historia de la traducción hacia distintas lenguas: cf. el Portal de la Historia de la traducción en España ${ }^{6}$.

Por otra parte, los manuales españoles no contemplan la lexicografía bilingüe con el español de una gran diversidad de lenguas, especialmente las minoritarias o alejadas geográfica o culturalmente, pero tampoco con las de otras lenguas hispanoamericanas o de buena parte de Europa: este gran vacío no está aún cubierto. Frente a la tradición anglosajona, más teórica y al servicio de la práctica, se da en nuestros manuales bastante importancia a la historia de los diccionarios, la cual, no obstante, debido a estas carencias, se aborda de forma incompleta y debería completarse.

Para ello, creemos que deberían ampliarse las miras y empezar a escribirse artículos con algunos pares de lenguas poco tratados en nuestra lexicografía: así, siguiendo con estudios previos como el realizado sobre los manuales de lenguas de regiones colonizadas (Pablo Núñez, 2017) y los vocabularios de regiones del Pacífico (cf. Proyecto ExploLex y https://cutt.ly/uR6ICuj y Pablo Núñez, 2021a y b), nos hemos puesto manos a la obra y hemos analizado la lexicografía bilingüe español-turco, desde sus orígenes en el siglo XVI hasta nuestros días, en otro trabajo que aparecerá próximamente (Pablo Núñez en prensa).

Asimismo, en otros estudios que tenemos en marcha mostraremos cómo estas mismas conclusiones vistas sobre los manuales se reflejan en los temarios

${ }^{6}$ https://cutt.ly/hR6IJ2h 
de la asignatura "Lexicografía" que se imparte en las distintas universidades españolas. Del mismo modo, comprobaremos cómo la tradición editorial comercial hispánica es causa también de la existencia de estas carencias, al no tener diccionarios suficientes con el español y lenguas periféricas, algo que no ocurre en la tradición editorial anglosajona.

\section{BIBLIOGRAFÍA}

Ahumada Lara, I. (Ed.) (2000). Cinco siglos de lexicografía del español. Publicaciones de la Universidad de Jaén.

Alvar Ezquerra, M. (2002). De antiguos y nuevos diccionarios del español. Arco/Libros.

Alvar Ezquerra, M. (2013). Las nomenclaturas del español: siglos XV-XIX. Liceus.

Álvarez de Miranda, P. (2011). Los diccionarios del español moderno. Trea.

Anglada Arboix, E. (2002). Lexicografía española. Universitat de Barcelona. (Textos docents; 272).

Atkins, B. T. S. \& Rundell, M. (2008). The Oxford Guide to Practical Lexicography. Oxford University Press.

Ayala Castro, A. M. ${ }^{a}$, \& Medina Guerra, A. M. ${ }^{a}$ (Ed. y Coord.) (2010). Diversidad lingüüstica y diccionario. Universidad, Servicio de Publicaciones.

Bajo Pérez, E. (2000). Diccionarios: introducción a la historia de la lexicografía del español. Ediciones Trea.

Brown, K., \& Anderson, A. (Eds.) (2006), Encyclopedia of Language and Linguistics, 2nd ed. Elsevier.

Bruña Cuevas, M. (Coord.) (2008), Lexicografía bilingüe y plurilingüe del español, número monográfico publicado en Philologia hispalensis, 22. https://doi.org/10.12795/ PH.2008.v22.i01

Campos Souto, M.; Cotelo García, R., \& Pérez Pascual, J. I. (Eds.) (2007). Historia de la lexicografía española. Universidade de A Coruña.

Cazorla Vivas, M. ${ }^{\text {a }}$ C. (2002). Lexicografía bilingüe de los siglos XVIII y XIX con el español y el francés. Universidad Complutense. https://cutt.ly/1R6PcKv

Considine, J. (2017). Small Dictionaries and Curiosity: Lexicography and Fieldwork in Post-Medieval Europe. Oxford University Press.

Considine, J. (Ed.) (2019). The Cambridge World History of Lexicography. Cambridge University Press.

Córdoba Rodríguez, F. (2001). Introducción a la lexicografía española. Univerzita Palackého.

Córdoba Rodríguez, F., González Seoane, E., \& Sánchez Palomino, M. ${ }^{a}$ D. (2014). Lexicografía de las lenguas románicas. De Gruyter Mouton. 2 vols. 
Cowie, A. P. (2009). The Oxford history of English Lexicography. Clarendon Press y Oxford University Press.

Durkin, P. (2016). The Oxford Handbook of Lexicography. Oxford University Press.

Fernández Urdaneta, H. (2010). Dictionaries in Spanish and English from 1554 to 1740 : Their Structure and Development. Diputación Provincial de Soria. (Vertere: monográficos de la revista Hermeneus; 10).

Fuertes-Olivera, P. A. (Ed.) (2018). The Routledge Handbook of Lexicography. Routledge.

Gallina, A. (1959). Contributi alla storia della lessicografia italo-spagnola del secoli XVI e XVII. Leo S. Olschki.

García-Medall Villanueva, J. (2009). Vocabularios hispano-asiáticos: traducción y contacto intercultural. Diputación Provincial de Soria. (Vertere: monográficos de la revista Hermeneus; 11).

Hanks, P., \& De Schryver, G.-M. (Eds.) (2015-2024). International Handbook of Modern Lexis and Lexicography. Springer.

Haensch, G., Wolf, L., Ettinger, S., \& Werner, R. (1982). La lexicografía: de la lingüística teórica a la lexicografía práctica. Gredos.

Haensch, G. (2004). Los diccionarios del español en el siglo XXI: problemas actuales de lexicografía: los distintos tipos de diccionarios, una guía para el usuario. Con la colab. de Carlos Omeñaca. 2. ${ }^{\text {a }}$ ed. corr. y aum. Universidad de Salamanca.

Hartmann, R. R. K. (Ed.) (1986). History of Lexicography: Papers from the Dictionary Research Centre Seminar at Exeter, March 1986. John Benjamins. (Amsterdam Studies in the Theory and History of Linguistic Science. Series III: Studies in the History of the Language Sciences; 40)

Hausmann, F. J. et al. (Ed.) (1989-1991; 2013). Wörterbücher: ein internationales Handbuch zur Lexikographie = Dictionaries: an International Encyclopedia of Lexicography = Dictionnaires : encyclopédie internationale de lexicographie. Walter de Gruyter, vols. 1-3; vol. 4, De Gruyter.

Jacinto García, E. (2004). "Historia de la lexicografía bilingüe español-japonés: un lazo entre Oriente y Occidente”. En T. Arimoto (Ed.), Japón y el mundo bispánico: enlaces culturales, literarios y lingüísticos (pp. 78-91). AEPE.

Jackson, H. (Ed.) (2013). The Bloomsbury Companion to Lexicography. Bloomsbury Academic.

Landau, S. (1984). Dictionaries: The Art and Craft of Lexicography. Scribner.

Landau, S. (2001). Dictionaries: The Art and Craft of Lexicography. 2nd ed. Cambridge University Press.

Martínez González, A. (2017). Temas de bistoria de la Lingüística. Universidad de Granada, Servicio de Publicaciones.

Martínez de Sousa, J. (1995). Diccionario de lexicografía práctica. Bibliograf.

Martínez de Sousa, J. (2009). Manual básico de lexicografía. Trea. 
Matoré, G. (1968): Histoire des dictionnaires français. Larousse.

Medina Guerra, A. M. ${ }^{a}$ (Coord.) (2003). Lexicografía española. Ariel.

Niederehe, H.-J. Bibliografía cronológica de la lingüística, la gramática y la lexicografía del español (BICRES). John Benjamins. (Amsterdam Studies in the Theory and History of the Language Sciences. Series III, varios vol.)

- Vol. 1. BICRES I: Desde los comienzos hasta el año 1600. 1994 (Series III; 76).

- Vol. 2. BICRES II: Desde el año 1601 hasta al año 1700. 1999 (Series III; 91).

— Vol. 3. BICRES III: Desde el año 1701 hasta al año 1800. 2005 (Series III; 108).

- Vol. 4. BICRES IV: Desde el año 1801 hasta al año 1860. En colaboración con M. Á. Esparza Torres,. 2012 (Series III; 118).

- Vol. 5. BICRES V: Desde el año 1861 hasta el año 1899. En colaboración con M. Á. Esparza Torres y la colaboración de A. Álvarez, E. Battaner y G. B. Garrido. 2015 (Series III; 124).

Pablo Núñez, L. (2010). El arte de las palabras: Diccionarios e imprenta en el Siglo de Oro. Editora Regional de Extremadura. 2 vols. (Colección Premios de Investigación Bibliográfica "Bartolomé José Gallardo").

Pablo Núñez, L. (2017). De Europa a África pasando por Indochina: Guías de conversación plurilingües para viajeros del siglo XIX y algunas notas sobre los manuales de lenguas de regiones colonizadas. ReCHERches: Culture et Histoire dans l'Espace Roman (Presses Universitaires de Strasbourg) 18, 153-169. https://cutt.ly/xR6OI7H

Pablo Núñez, L. (2020). Recursos para la traducción en los Siglos de Oro: gramáticas y diccionarios. En: F. Lafarga y L. Pegenaute (Coords.), Historia de la traducción en España, Portal de Historia de la traducción en España. https://cutt.ly/hR6OGXK

Pablo Núñez, L. (2021a). Hacia un tesoro de voces indígenas recogidas en las expediciones científicas de los siglos XVIII-XIX. En M. De Beni, M. \& D. Hourani-Martín (Eds.), Corpus y estudio diacrónico del discurso especializado en español (pp. 139-165). Peter Lang, (Studien zur romanischen Sprachwissenschaft und interkulturellen Kommunikation; 161).

Pablo Núñez, L. (2021b). The vocabulary of Easter Island (ca 1770) and the indigenous voices collected in the Spanish and English scientific expeditions of 18th century. En 11th International Conference on Historical Lexicography and Lexicology-ICHLL11 (Logroño, June 16-18, 2021).

Pablo Núñez, L. (en prensa). An approach to the history of Spanish-Turkish bilingual dictionaries.

Porto Dapena, J.-Á. (2002). Manual de técnica lexicográfica. Arco Libros.

Quemada, B. (1968). Les dictionnaires du français moderne, 1539-1863: Étude sur leur histoire, leurs types et leurs méthodes. Didier.

Quirós García, M. et al. (Eds.) (2016). Etimología e historia en el léxico del español: Estudios ofrecidos a José Antonio Pascual (Magister bonus et sapiens). Iberoamericana; Vervuert. 
Rafel i Fontanals, J. (2005). Lexicografia. Editorial UOC.

Rodríguez Barcia, S. (2016). Introducción a la lexicografía. Síntesis.

Rojo-Mejuto, Natalia (2018). Los inicios de la lexicografía hispano-japonesa. Revista de Lexicografía, 24, 143-169. https://doi.org/10.17979/rlex.2018.24.0.5522

San Vicente, F. (Dir.) (2008). Textos fundamentales de la lexicografía italoespañola (19172007). Polimetrica.

San Vicente, F. (Dir.) (2010). Textos fundamentales de la lexicografía italoespañola (18051916). Polimetrica.

Sariego López, I., Gutiérrez Cuadrado, J.; \& Garriga Escribano, C. (Eds.) (2017). El diccionario en la encrucijada: De la sintaxis y la cultura al desafío digital. Universidad de Cantabria, Escuela Universitaria de Turismo Altamira y Asociación Española de Lexicografía Hispánica.

Steiner, J. (1970). Two centuries of Spanish and English Bilingual Lexicography (1590-1800). Mouton. Reed; De Gruyter 2015.

Svensén, B. (2009). Handbook of Lexicography: The Theory and Practice of DictionaryMaking. Cambridge: Cambridge University Press.

Van Sterkenburg, P. (Ed.) (2003). A Practical Guide to Lexicography. John Benjamins.

Wiegand, H. E. (1984). On the structure and contents of a general theory of Lexicography. En R. R. K. Hartmann (Ed.), LEXeter '83: proceedings (Papers from the International Conference on Lexicography at Exeter, 9-12 September 1983). Max Niemeyer (reed.: Berlin/Boston: De Gruyter, Inc., 2017). https://cutt.ly/xR6PdHv

Zgusta, L. (1971). Manual of Lexicography. Academia; Mouton. 